\title{
Heart rate variability and its relation to ventricular arrhythmias in congestive heart failure
}

\author{
Lü Fei, Philip J Keeling, Jaswinder S Gill, Yaver Bashir, Deborah J Statters, \\ Jan Poloniecki, William J McKenna, A John Camm
}

\author{
Department of \\ Cardiological \\ Sciences, St George's \\ Hospital Medical \\ School, London \\ L Fei \\ P J Keeling \\ J S Gill \\ Y Bashir \\ D J Statters \\ J Poloniecki \\ W J McKenna \\ A J Camm \\ Correspondence to: \\ Dr Lü Fei, Department of \\ Cardiological Sciences, \\ St George's Hospital \\ Medical School, Cranmer \\ SW17 0RE. \\ Accepted for publication \\ 13 October 1993
}

rate variability is principally related to the degree of left ventricular impairment and is independent of aetiology and the presence of ventricular arrhythmias. The data suggest that analysis of heart rate variability does not help the identification of patients with congestive heart failure at increased risk of sudden death.

(Br Heart f 1994;71:322-328)

Methods-Spectral heart rate variability was analysed from 24 hour ambulatory electrocardiograms in 15 controls, 15 patients with non-sustained ventricular tachycardia associated with clinically normal hearts (NHVT group), and 40 patients with congestive heart failure (CHF group) secondary to either ischaemic heart disease $(n=15)$ or idiopathic dilated cardiomyopathy $(n=25)$. Of the 40 patients with congestive heart failure 15 had no appreciable ventricular arrhythmias (ventricular extrasystoles < 10 beats / $h$ and no salvos) and formed the CHF-VA ${ }^{-}$group. Another 15 patients with congestive heart failure and nonsustained ventricular tachycardia formed the CHF-NSVT group.

Results-Heart rate variability was significantly lower in the CHF group than in controls (mean (SD) total frequency 23 (12) $v 43$ (13) ms; low frequency 12 (8) $v$ 28 (9) ms; high frequency 8 (5) $v 14$ (7) ms; $p<0.001)$. The differences in heart rate variability between controls and the NHVT group, between ischaemic heart disease and dilated cardiomyopathy, and between the CHF-VA- and CHF-NSVT groups were not significant. In the CHF group heart rate variability was significantly related to left ventricular ejection fraction but not associated with ventricular arrhythmias. The frequency of ventricular extrasystoles was significantly related to the high frequency component of heart rate variability $(r=0.54, p<$ 0.05 ) in the NHVT group. Stepwise multiple regression analysis showed that in the CHF group, heart rate variability was predominantly related to left ventricular ejection fraction $(p<0.05)$. There was no significant difference in heart rate variability between survivors $(n=34)$ and those who died suddenly $(n=6)$ at one year of follow up in the CHF group.

Conclusion-In patients with congestive heart failure, heart rate variability is significantly decreased. The depressed heart
Ventricular arrhythmias often occur in patients with compromised cardiac function ${ }^{12}$ and seem to be significantly related to impairment of left ventricular function. ${ }^{3-5}$ The underlying mechanisms of the ventricular arrhythmogenesis in these patients remain to be fully elucidated. Although some studies have noted an association between the presence of frequent ventricular extrasystoles or non-sustained ventricular tachycardia and risk of sudden cardiac death in patients with congestive heart failure, there are substantial controversies about the prognostic value of ventricular arrhythmias in these patients. ${ }^{26-8} \mathrm{It}$ has been reported that many invasive and non-invasive techniques, such as the signal averaged electrocardiogram and electrophysiological study, are not helpful for identification of those patients with congestive heart failure who are at risk of sudden cardiac death. ${ }^{6}$ Recently, analysis of heart rate variability has provided a non-invasive measure of autonomic influence on the heart and can be used for risk stratification in patients after a myocardial infarction. ${ }^{9-13}$ Its prognostic significance in patients with congestive heart failure, however, remains unknown.

The finding that heart rate variability is decreased in patients with congestive heart failure suggests that there is a significant alteration of autonomic activity in these patients. ${ }^{14-16}$ Whether the most often found ventricular arrhythmias are related to the altered autonomic tone in patients with congestive heart failure remains unknown. It has been reported that heart rate variability is also decreased in electrically unstable patients susceptible to ventricular arrhythmias. ${ }^{17-20}$ Therefore, heart rate variability may be associated with both the electrical and the mechanical function of the heart. The determinants of heart rate variability have not yet been well described in patients with both congestive heart failure and ventricular arrhythmias.

In this case-control study, we aimed to 
assess $(a)$ heart rate variability in patients with congestive heart failure and ventricular arrhythmias, (b) the effects of different aetiologies of congestive heart failure (either ischaemic heart disease or idiopathic dilated cardiomyopathy) on heart rate variability, (c) the relation between heart rate variability and the frequency and severity of ventricular arrhythmias in the presence of congestive heart failure, and (d) the prognostic significance of the analysis of heart rate variability in patients with congestive heart failure.

\section{Patients and methods \\ PATIENTS}

In this investigation, heart rate variability was studied in normal subjects, patients with idiopathic ventricular tachycardia, and patients with congestive heart failure with and without ventricular tachycardia (table 1). Fifteen healthy subjects ((eight men), mean (SD) age 47 (10) years) served as controls. None of them had significant cardiac or other medical problems, and their 12 lead and 24 hour ambulatory electrocardiograms were normal. Fifteen patients (nine male), age 41 (13), with non-sustained ventricular tachycardia associated with clinically normal hearts formed the NHVT group. Non-sustained ventricular tachycardia was defined as uniform broad QRS complexes lasting from $\geqslant 3$ beats to < $30 \mathrm{~s}$ and ending spontaneously without haemodynamic compromise, with an effort to match the number of beats in the longest salvos to patients with congestive heart failure and salvos. All of the NHVT group were normal on physical examination, chest radiography, resting electrocardiograms, echocardiography (including right ventricular views), left ventricular angiography, and coronary artery angiography. Left ventricular ejection fraction (LVEF) was $>55 \%$. Right ventricular endomyocardial biopsy was normal in all except two patients who had mild non-specific fibrosis of uncertain clinical significance.

Sixty patients with congestive heart failure in the New York Heart Association functional classes II to IV secondary to either ischaemic heart disease or idiopathic dilated cardiomyopathy were enrolled in this study. Congestive heart failure was defined as exertional dyspnoea or fatigue for more than six months, a dilated left ventricle, and a LVEF $\leqslant 40 \%$ at rest determined by angiography or radionuclide ventriculography. Twenty patients were excluded because of sinus node dysfunc-

Table 1 Clinical characteristics of controls and patients with congestive heart failure

\begin{tabular}{llllll}
\hline & Controls & NHVT & CHF & CHF-VA- & CHF-NSVT \\
\hline No & 15 & 15 & 40 & 15 & 15 \\
Mean (SD)) age (yr) & $47(10)$ & $41(13)$ & $50(12)$ & $48(9)$ & $51(14)$ \\
Sex (men/women) & $8 / 7$ & $9 / 6$ & $22 / 28$ & $11 / 4$ & $14 / 1$ \\
Ventricular arrhythmias & None & NSVT & - & OVEs & NSVT \\
Mean (SD)) LVEF (\%) & - & $>55$ & $26(8)$ & $26(5)$ & $24(8)$ \\
\hline
\end{tabular}

$\mathrm{CHF}$, congestive heart failure; $\mathrm{CHF}-\mathrm{VA}^{-}$congestive heart failure without significant ventricula arrhythmias; CHF-NSVT, congestive heart failure with non-sustained ventricular tachycardia NHVT, clinically normal heart associated with salvos; NSVT, non-sustained ventricular tachycardia; OVEs, occasional ventricular extra systoles. tion (three), atrial fibrillation (two), abnormal atrioventricular conduction (one), artificial ventricular pacing (permanent pacemaker one and implantable cardioverter defibrillator one), noisy recording of Holter tapes (three), and antiarrhythmic drug treatment (nine). In the remaining 40 patients with congestive heart failure (the CHF group) there were 15 patients with ischaemic heart disease (14 men) and 25 patients with idiopathic dilated cardiomyopathy (eight men). All 40 of the CHF group were taking diuretics $(40-120 \mathrm{mg}$ frusemide / day) and two were taking digoxin. None of the 40 patients was being treated with antiarrhythmic drugs or had other severe medical disorders. Of the 40 patients in the CHF group 15 (11 men) had no significant ventricular arrhythmias (ventricular extrasystoles $<10$ beats $/ \mathrm{h}$ and no non-sustained ventricular tachycardia) and formed the CHF-VA $^{-}$group. They consisted of seven patients with ischaemic heart disease and eight patients with idiopathic dilated cardiomyopathy. Another 15 patients (14 men) in the CHF group who showed non-sustained ventricular tachycardia on Holter monitoring were taken to be the CHF-NSVT group. They consisted of four patients with ischaemic heart disease and 11 with idiopathic dilated cardiomyopathy. This subgrouping of patients within the CHF group according to the presence or absence of non-sustained ventricular tachycardia was designed to specifically assess the influence of the presence of non-sustained ventricular tachycardia on heart rate variability in patients with congestive heart failure compared with those without cardiac dysfunction, (the NHVT group). Therefore 10 of the CHF group with frequent ventricular extrasystoles but without ventricular tachycardia were not categorised in either group CHF-VA ${ }^{-}$or CHF-NSVT. The definition of ventricular arrhythmias was based on data from the same Holter electrocardiograms from which heart rate variability was calculated in this study.

ANALYSIS OF HEART RATE VARIABILITY

All subjects underwent two channel (modified V5 and V1 leads) 24 hour ambulatory electrocardiographic monitoring (Marquette Series $8500)$. Heart rate variability was analysed from the 24 hour ambulatory electrocardiogram with a Holter analysis system (Marquette Series 8000, digitisation frequency $128 \mathrm{~Hz}$ ). After classification of the QRS morphology the longest and the shortest $R R$ intervals on the $R R$ interval histogram were manually confirmed until no QRS complex was mislabelled as either an artifact or an extrasystole. The largest and the smallest RR ratios on the $R R$ ratio histogram were also visually checked to ensure that all normal and abnormal QRS complexes on the ambulatory electrocardiogram were correctly labelled. When calculating the heart rate variability values, only normal to normal intervals were used. Each interval that was to be excluded due to extrasystoles or artifacts was replaced by holding the previous coupling interval level 
throughout the time interval to the next valid coupling interval. The beat to beat fluctuations were transformed to frequency domain by fast Fourier transformation and the spectral measures were computed as the square root of areas under the power spectrum. In this study, heart rate variability was expressed as total (TF, $0.01-1.00 \mathrm{~Hz})$, low (LF, $0.04-0.15 \mathrm{~Hz}$ ), and high (HF, $0 \cdot 15-0.40 \mathrm{~Hz})$ frequency components.

\section{STATISTICAL ANALYSIS}

Unpaired Student's $t$ test, analysis of variance, and multivariate correlation and regression analysis were used where appropriate. Because of the relation of heart rate variability to age, ${ }^{21-23}$ analysis of covariance (with age as a covariate) was used to compare the between group differences in values of heart rate variability adjusted for the influence of age. Stepwise multiple regression analysis was used to assess the relations of heart rate variability with other clinical variables. All data are expressed as means (SD). The frequency of ventricular arrhythmias was normalised as necessary by logarithmic transformation. A two tailed $\mathrm{p}$ value $<0.05$ was considered significant.

\section{Results}

There was no significant difference between groups in age for any comparisons (table I) except between the NHVT and the CHFNSVT groups (41 (13) v 51 (14), $\mathrm{p}<0.05$ ), and between patients with ischaemic heart disease and idiopathic dilated cardiomyopathy (59 (6) v 44 (12), $\mathrm{p}<0.001$ ). No significant differences were found in LVEF between patients with ischaemic heart disease and idiopathic dilated cardiomyopathy $(25 \%(5 \%) v$ $25 \%(10 \%) \mathrm{NS}$ ), or between the CHF-VA and the CHF-NSVT groups $(26 \%$ (5\%) $v$ $24 \%$ (8\%) NS).

\section{MEAN HEART RATE}

There was no significant difference in mean heart rate between controls and the NHVT group (69 (9) $v 67$ (12) beats/min NS), or between the CHF-VA ${ }^{-}$and the CHF-NSVT groups (86 (8) $v 88$ (14) beats/min NS). The difference in mean heart rate was statistically significant between patients with ischaemic

Table 2 V Values for the between group differences in heart rate variability

\begin{tabular}{|c|c|c|c|c|}
\hline Component of heart rate variability & Controls & NHVT & $C H F-V A^{-}$ & CHF-NSVT \\
\hline Mean (SD) TF (ms) & 43(13) & $48(14)$ & $26(9)$ & $23(12)$ \\
\hline Controls & - & - & - & - \\
\hline NHVT & $=0.63$ & - & - & - \\
\hline CHF-VA- & $<0.001$ & $<0.001$ & - & - \\
\hline CHF-NSVT & $<0.001$ & $<0.001$ & $=0.71$ & - \\
\hline Mean (SD) LF (ms) & $28(9)$ & $33(11)$ & $15(6)$ & $13(8)$ \\
\hline Controls & - & - & - & - \\
\hline NHVT & $=0.44$ & - & - & - \\
\hline CHF-VA $^{-}$ & $<0.001$ & $<0.001$ & - & - \\
\hline CHF-NSVT & $<0.001$ & $<0.001$ & $=0.74$ & $\overline{-}$ \\
\hline Mean (SD) HF (ms) & $14(7)$ & $15(6)$ & $8(4)$ & $7(4)$ \\
\hline Controls & - & - & - & 一 \\
\hline NHVT & $=0.94$ & - & - & - \\
\hline CHF-VA- & $<0.001$ & $=0.005$ & $=0.40$ & - \\
\hline CHF- & & & -0.40 & - \\
\hline
\end{tabular}

Abbreviations as in table 1.
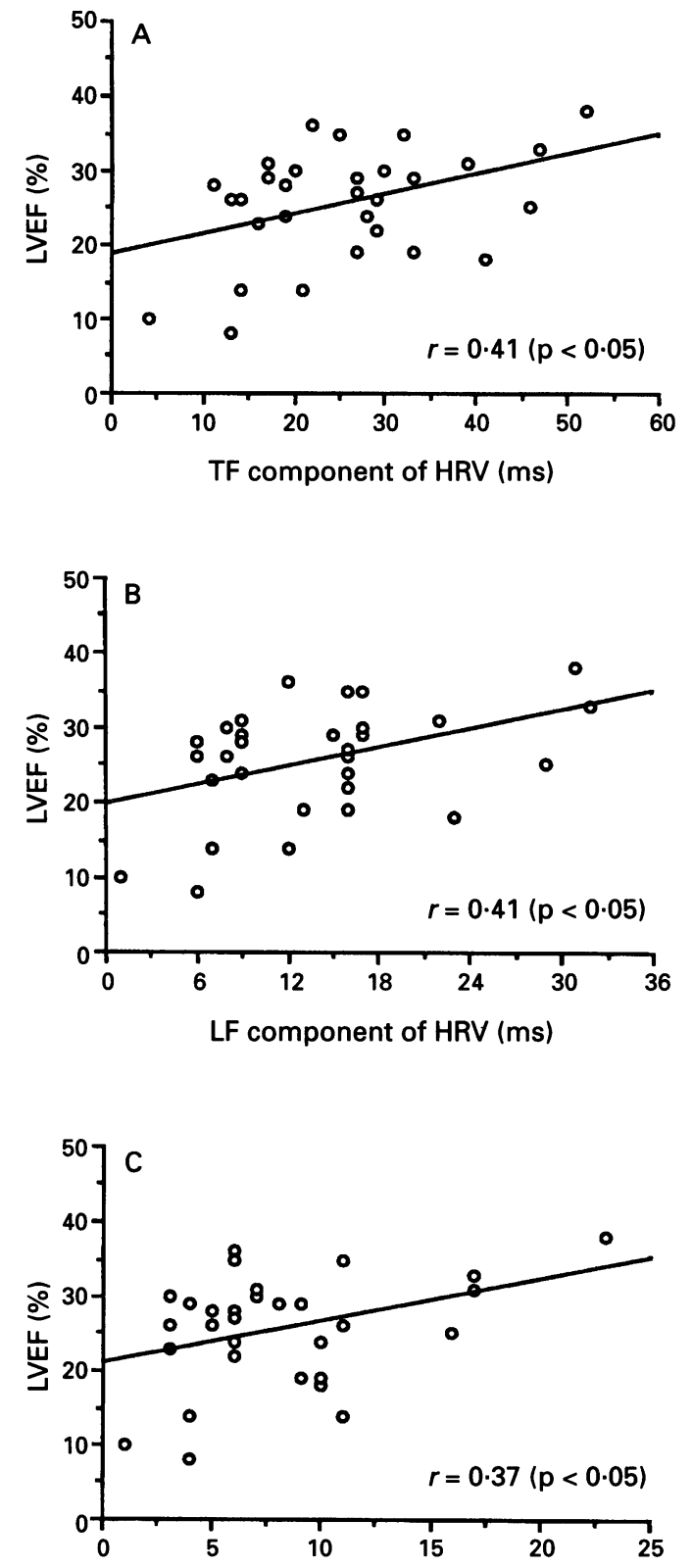

HF component of HRV (ms)

Figure 1 Association of (A) TF, (B) $L F$, and (C) $H F$ components of heart rate variability (HRV) with LVEF in patients with congestive heart failure.

heart disease and idiopathic dilated cardiomyopathy (83 (8) $v 91$ (14) beats $/ \mathrm{min}, \mathrm{p}=$ $0 \cdot 023)$. Mean heart rate was significantly higher in the CHF group than in the controls (88 (12) v 69 (9) beats/min, $\mathrm{p}<0.001$ ). Mean heart rate was also significantly $(p<$ 0.001) higher in the CHF-VA ${ }^{-}$and the CHFNSVT groups compared with controls and the NHVT group.

\section{HEART RATE VARIABILITY}

There was no significant difference in heart rate variability between controls and the NHVT group (TF, 43 (13) $v 48$ (14) ms; LF, 28 (9) v 33 (11) ms; and HF, 14 (7) v 15 (6) ms; NS), between the CHF-VA- and CHFNSVT groups (TF, 26 (9) $v 23$ (12) ms; LF, 15 (6) $v 13$ (8) ms; and HF, 8 (4) v 7 (4); NS), or between patients with ischaemic heart 
Figure 2 Total number of ventricular extrasystoles extrasystolic complexes (VEs) during the 24 hour recordings $v$ frequency components of heart rate variability (HRV), (A), $T F(B) L F$, and (C) $H F$ in patients with congestive heart failure and VEs $\geqslant 10$ beats/h (NS).
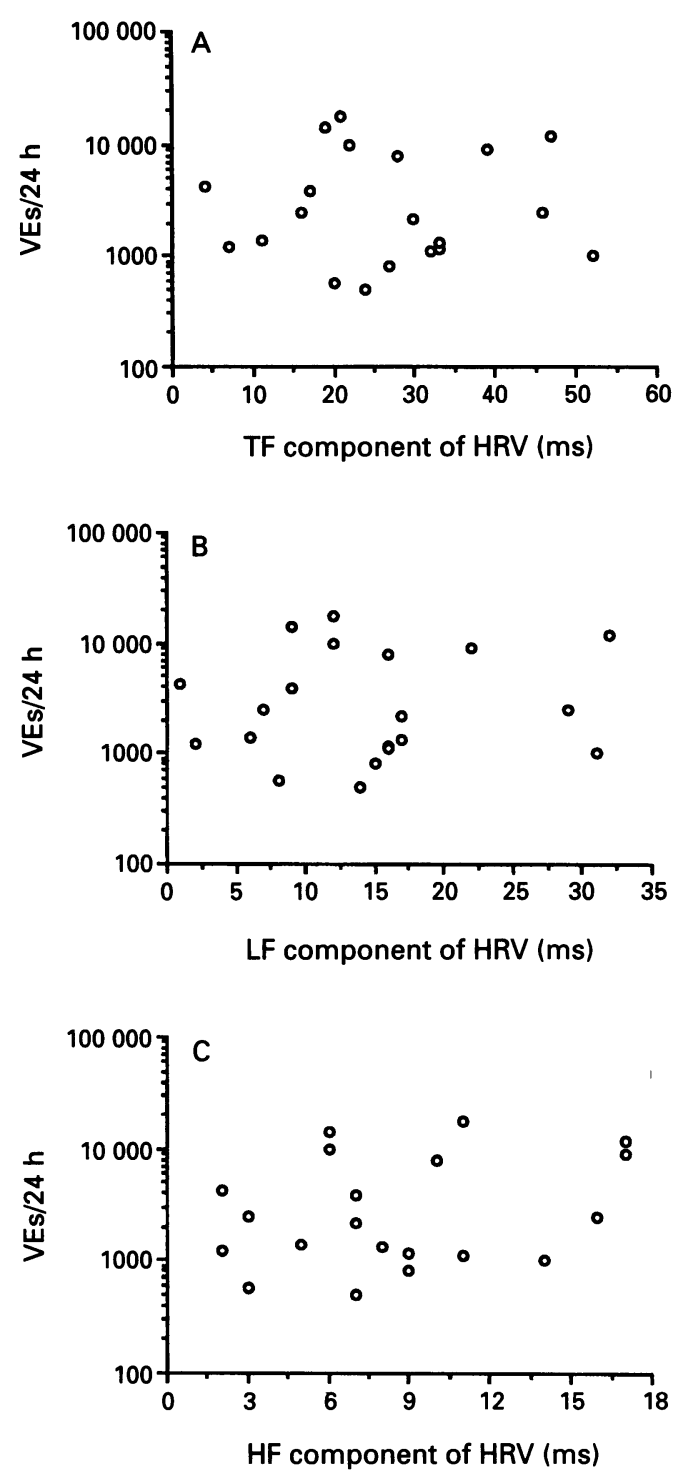

disease and idiopathic dilated cardiomyopathy (TF, 23 (10) v 23 (13) ms; LF, 12 (6) $v 13$ (9) $\mathrm{ms}$; and HF, 7 (4) $v 8$ (6) $\mathrm{ms}$; NS). The difference in heart rate variability, however, was highly significant between the CHF group and the controls (TF, 23 (12) v 43 (13) $\mathrm{ms}$; $\mathrm{LF}, 12$ (8) v 28 (9) ms; HF, 8 (5) $v 14$ (7) ms; $\mathrm{p}<0.001)$. Heart rate variability was significantly lower in the CHF-VA- and the CHFNSVT groups than in controls and the NHVT group (table 2).

CORRELATIONS BETWEEN HEART RATE VARIABILITY AND OTHER CLINICAL MEASURES Heart rate variability was inversely related to age in controls (TF, $r=-0.54$; LF, $r=$ -0.63 ; and HF, $r=-0.55$; $\mathrm{p}<0.05)$, but not in the CHF group (TF, $r=-0.03$; LF, $r=$ -0.09 ; and HF, $r=-0.01$; NS). There was a significant relation between heart rate variability and LVEF in the CHF group (figure 1).

It has been shown that the total number of ventricular extrasystoles and the number of beats in the longest salvos of ventricular extrasystoles over a 24 hour period may be associated with a poor prognosis in patients with congestive heart failure. ${ }^{672425} \mathrm{We}$ there-
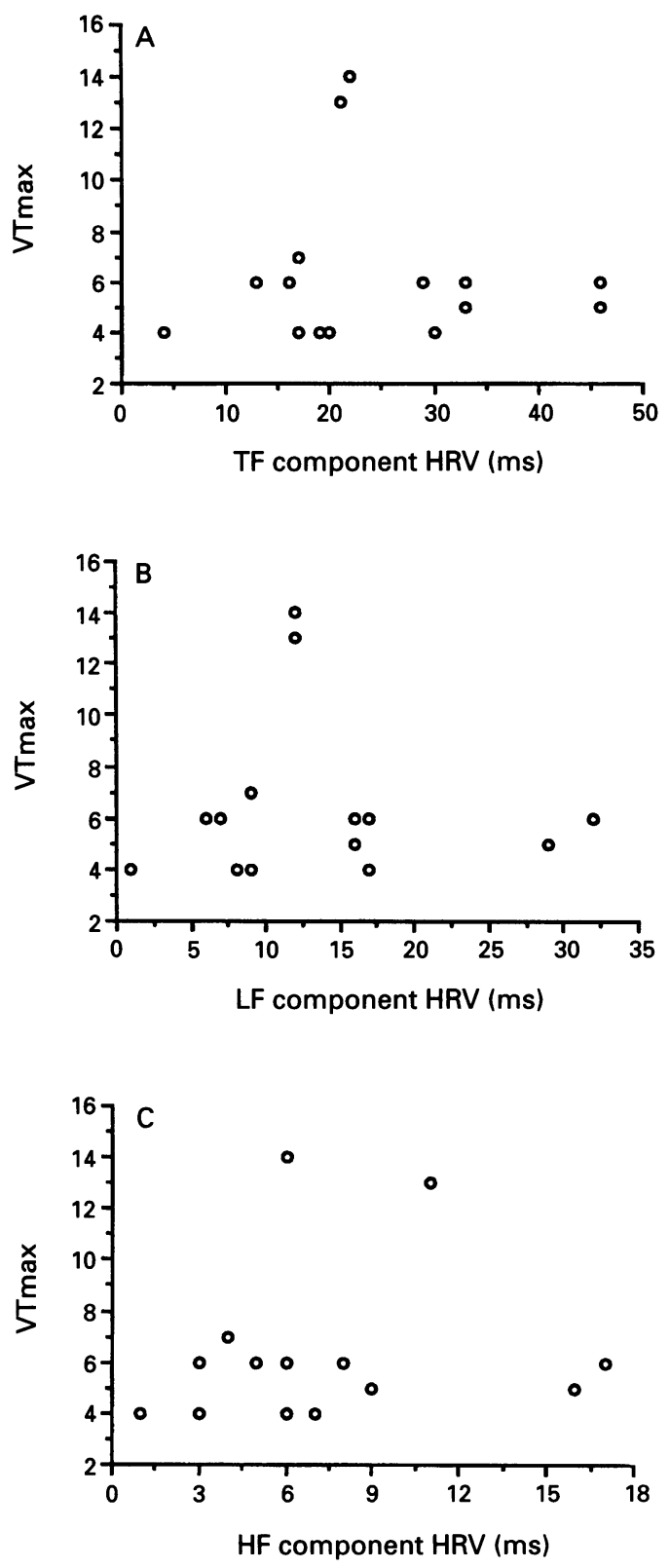

Figure 3 Number of beats in the longest salvo of ventricular extrasystoles (VTmax) during 24 hour recordings $v$ frequency components of heart rate variability (HRV)-namely, (A) TF, (B) LF, and (C) HF-in patients with congestive heart failure and salvos (NS).

fore examined their association with heart rate variability in patients with congestive heart failure and ventricular arrhythmias. No significant associations could be found in these patients before or after logarithmic transformation (figs 2 and 3). Neither the total number of ventricular extrasystoles $(r=0 \cdot 11, \mathrm{NS})$ nor the number of beats for the longest episode of salvos $(r=0 \cdot 15$; NS) over the 24 hour recordings was significantly related to LVEF in patients with congestive heart failure. As peak oxygen consumption during exercise may also be related to a poor prognosis in patients with congestive heart failure, ${ }^{26}{ }^{27}$ we correlated peak oxygen consumption during exercise with heart rate variability. No significant correlation was found between them (TF, $r=0 \cdot 23$; LF, $r=0.18$; HF, $r=0.23$; NS). Based on stepwise multivariate regression analysis, of 
Figure 4 Relation

between the total number of ventricular extrasystoles (VEs) during the 24 hour recordings and the frequency components of heart rate variability (HRV), (A) TF, (B) LF, and (C) $H F$ in patients with idiopathic ventricular tachycardia.
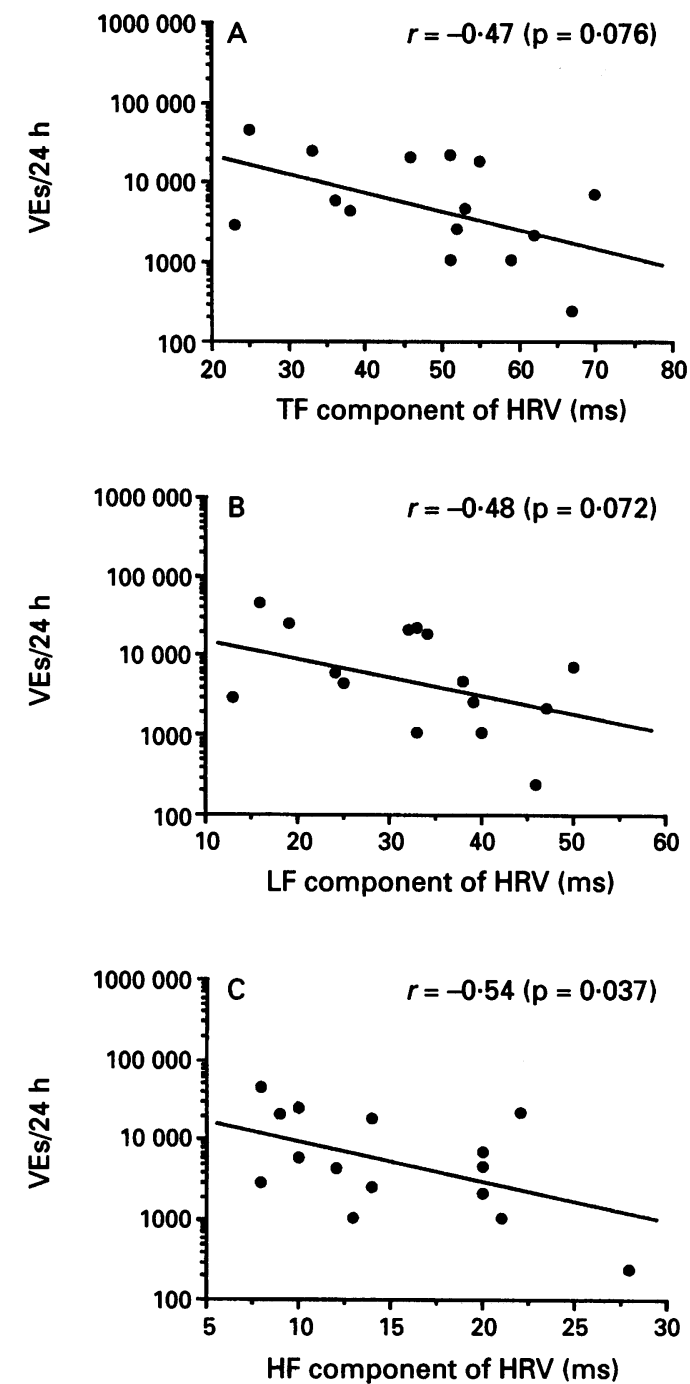

the predictive variables including age, LVEF, peak oxygen consumption during exercise, the number of beats for the longest episode of salvos, and the logarithmic value of the total number of ventricular extrasystoles on 24 hour recordings, heart rate variability was shown to be predominantly related to LVEF in patients with congestive heart failure.

Figure 4 shows the relation between heart rate variability and the total number of ventricular extrasystoles over 24 hours in patients with NHVT. Stepwise multivariate regression analysis showed that the total number of ventricular extrasystoles over 24 hours was predominantly related to the $\mathrm{HF}$ component of heart rate variability $(r=0.54, \mathrm{p}<0.05)$. There was no significant relation between the number of beats in the longest episode of salvos and heart rate variability in these patients (TF, $r=0.43$; LF, $r=0.39$; and $\mathrm{HF}$, $r=0 \cdot 17$; NS).

\section{FOLLOW UP}

All patients with congestive heart failure were followed up in a heart failure clinic at least every three months. Patient deaths were identified by direct communication with the patients' families and their general practitioners. Every effort was made to discriminate sudden death from pump failure. As in the cardiac arrhythmia pilot study sudden death in this study was defined as death within one hour of the onset of new symptoms. ${ }^{28}$ The definition also included instantaneous death, death during sleep, and unwitnessed death that occurred within one hour of the patient last being seen alive. In all cases death certificates and necropsy reports were examined to establish cause of death. During one year of follow up of the 40 patients with congestive heart failure, nine patients died and six patients underwent heart transplantation.

Of the nine patients who died, six died suddenly (one of them had been resuscitated from sudden death). One of the six who died suddenly had ischaemic heart disease, and the other five had idiopathic dilated cardiomyopathy. These patients who died suddenly were significantly younger than the survivors (41(14) $v$ 52(11) years, $p<0.05)$. After excluding patients with ischaemic heart disease, the difference in age between patients who died suddenly and those who survived among patients with idiopathic dilated cardiomyopathy was still significant (32(5) $v$ $47(11)$ years, $p<0.01$ ). There was no significant difference in LVEF between survivors and patients who died suddenly $(25 \%(8 \%) v$ $27 \%(9 \%)$ NS). The difference in heart rate variability between patients who died suddenly and survivors was not significant (TF, 29(18) v 23(11) ms; LF, 17(12) v 12(7) ms; $\mathrm{HF}, 10(8) v 8(5) \mathrm{ms}$; NS).

\section{Discussion}

The finding in this study that heart rate variability was significantly decreased in patients with congestive heart failure is consistent with previous reports. ${ }^{14-16}$ Although heart rate variability has been shown to decrease with age in normal subjects, ${ }^{21-23}$ it seems unlikely that the difference in heart rate variability between patients with normal and abnormal left ventricular function was due to the difference in age, as there was no significant difference in age between these two groups and the difference in heart rate variability remained significant after statistical adjustment was made for age. None of our patients was receiving antiarrhythmic drug treatment and only two patients were taking digoxin. There is no evidence to suggest that frusemide decreases heart rate variability in patients with congestive heart failure. Therefore, the effects of drugs would also not seem to explain the significant decrease in heart rate variability in these patients.

The low frequency component of heart rate variability gives a measure of sympathetic activity with some influence from vagal activity, ${ }^{29} 30$ whereas the high frequency component is almost exclusively modulated by vagal activity..$^{30} 31$ Overall heart rate variability is thought to be mainly influenced by cardiac vagal activity. ${ }^{32-34}$ The finding that heart rate variability was decreased in patients with congestive heart failure suggests that there is an abnormal autonomic influence on the heart in these patients. It has been reported that $\beta$ blockers rather than class I antiarrhythmic 
agents can reduce the risk of sudden cardiac death in patients with a low LVEF. ${ }^{35}$ This beneficial action of $\beta$ blockers may result from an improvement in the abnormal autonomic activity. Eriksson and colleagues have reported that heart rate variability (measured as the mean difference in duration of consecutive $R R$ intervals in relation to the mean duration of $R R$ intervals from 10 minutes of electrocardiographic recording in the supine position and expressed as a percentage) may be an independent risk factor for heart failure. ${ }^{36}$ These findings suggest that abnormal autonomic activity may contribute importantly to the pathophysiology of congestive heart failure.

In this study, heart rate variability was significantly related to LVEF in patients with congestive heart failure. This is consistent with previous reports. ${ }^{1637}$ In the study of Saul et al there was a weak correlation $(r \bumpeq 0.5)$ between the low frequency component $(0.04-0.07 \mathrm{~Hz})$ of heart rate variability and haemodynamic variables including cardiac index and pulmonary artery wedge pressure. ${ }^{16}$ A similar correlation between heart rate variability and LVEF has recently been reported by Nolan et al $(r=0.49, \mathrm{p}<0.05) .{ }^{37}$ Among the clinical variables that indicate a poor prognosis in patients with congestive heart failure, multivariate analysis showed that LVEF was the single best independent determinant of heart rate variability in these patients. On the other hand, in our study heart rate variability was significantly depressed in patients with impaired left ventricular function irrespective of the different aetiologies of disease and the frequency and severity of ventricular arrhythmias (discussed later). Thus severity of myocardial dysfunction would seem to be an important determinant of heart rate variability in patients with both congestive heart failure and ventricular arrhythmias. In multivariate analysis of patients after a myocardial infarction, ${ }^{38}$ variables reflecting the mechanical state of the left ventricle are better at predicting cardiac mortality than those reflecting the electrical state of the heart. The overwhelming modulation of heart rate variability by left ventricular function in a failing heart may be responsible for the non-significant relation between age and heart rate variability in patients with congestive heart failure. Also the decrease in heart rate variability with age in normal subjects may be, at least in part, due to depressed nervous reflexes in elderly people. ${ }^{39}$ It is worth noting that the determinants of heart rate variability in patients with congestive heart failure may be quite different from those in normal subjects although this remains to be fully elucidated.

It is well known that the autonomic nervous system plays an important part in the pathogenesis of ventricular arrhythmias and sudden cardiac death. ${ }^{40}$ The role of autonomic activity in the genesis of ventricular tachycardias in congestive heart failure, however, remains uncertain. In this study, we compared heart rate variability between patients with and without non-sustained ven- tricular tachycardia and attempted to correlate directly the frequency and severity of ventricular arrhythmias with heart rate variability. In patients with salvos associated with clinically normal hearts, the frequency of ventricular extrasystoles over 24 hours of recording was significantly related to the high frequency component of heart rate variability. This accords with the hypothesis that vagal activity may have protective effects in preventing the development of ventricular tachycardias and sudden cardiac death. ${ }^{40}$ There was, however, no significant difference in heart rate variability in patients with and without non-sustained ventricular tachycardia in the presence of congestive heart failure in this study. We also did not find any significant association between heart rate variability and the frequency and severity of ventricular arrhythmias, which have otherwise been shown to be related to a poor prognosis in these patients. It has been shown that there is considerable spontaneous variability of ventricular arrhythmias on Holter electrocardiographic monitoring from recording to recording. ${ }^{41}{ }^{42}$ It seems unlikely that the non-significant relations were due to the variability of arrhythmias as ventricular arrhythmias were identified from the same Holter recordings from which heart rate variability was calculated. This suggests that the overall depression of heart rate variability in patients with congestive heart failure may not be the main substrate for ventricular arrhythmogenesis. Cardillo et al have reported that there was no relation between the severity of ventricular extrasystoles and autonomic outflow to the heart as detected by analysis of heart rate variability in hypertensive patients without heart failure. ${ }^{43}$ Diverse pathophysiological mechanisms underlying arrhythmogenesis may be one explanation for the different findings in the different clinical settings. Although our results cannot preclude the possibility of a role for the autonomic nervous system in the pathogenesis of ventricular arrhythmias in patients with congestive heart failure, they do not support this hypothesis.

It has been shown that decreased heart rate variability is an independent risk factor in patients after acute myocardial infarction. Like the signal averaged electrocardiogram and electrophysiological study, ${ }^{6}$ our findings do not suggest that analysis of heart rate variability will be helpful in identifying patients at risk of sudden cardiac death in the presence of congestive heart failure. This may be due to the diverse mechanisms of sudden cardiac death as well as ventricular tachycardias in congestive heart failure, such as bradycardia or electromechanical dissociation. ${ }^{44}$ Another possible explanation may be the predominant influence of LVEF on heart rate variability. A larger prospective study is warranted to fully define the predictive value of heart rate variability in patients with congestive heart failure in different functional classes.

1 Bethge C, Motz W, von Hehn A, Strauer BE. Ventricular arrthythmias in hypertensive heart disease with and without heart failure. $f$ Cardiovasc Pharmacol 1987; 10:S119-28. 
2 Maskin CS, Siskind SJ, LeJemtel TH. High prevalence of nonsustained ventricular tachycardia in severe congestive heart failure. Am Heart $f$ 1984;107:896-901.

3 Marchlinski FE, Buxton AE, Waxman HL, Josephson ME. Identifying patients at risk of sudden death after myocardial infarction: value of the response to programmed stimulation, degree of ventricular ectopic activity and severity of left ventricular dysfunction. $A m \mathcal{F}$ Cardiol 1983;52:1 190-6.

4 Meredith IT, Broughton A, Jennings GL, Esler MD Evidence of a selective increase in cardiac sympathetic activity in patients with sustained ventricular arrhythmias. $N$ Engl $₹$ Med 1991;325:618-24.

5 Gradman AH, Cunningham M, Harbison MA, Berger HJ, Zaret BL. Effects of oral digoxin on ventricular ectopy and its relation to left ventricular function. $A m \mathcal{F}$ Cardio 1983;51:765-9.

6 Podrid PJ, Fogel RI, Fuchs TT. Ventricular arrhythmia in congestive heart failure. Am $\mathcal{F}$ Cardiol 1992;69: in conges

7 Tamburro $P$, Wilber D. Sudden death in idiopathic dilated cardiomyopathy. Am Heart f 1992;124:1035-45.

8 Packer M. Lack of relation between ventricular arrhythmias and sudden death in patients with chronic heart failure. Circulation 1992;85(suppl I):I-50-6.

9 Farrell TG, Bashir Y, Cripps T, Malik M, Poloniecki J Bennett ED, et al. Risk stratification for arrhythmic events in postinfarction patients based on heart rate variability, ambulatory electrocardiographic variables and the signal-averaged electrocardiogram. I $\mathrm{Am} \mathrm{Coll}$ Cardiol 1991;18:687-97.

10 Singer DH, Martin GJ, Magid N, Weiss JS, Schaad JW, Kehoe $\mathrm{R}$, et al. Low heart rate variability and sudden cardiac death. F Electrocardiol 1988;21:S46-55.

11 Cripps TR, Camm AJ. Prediction of arrhythmic events in patients following myocardial infarction. Clin Cardiol 1989;12:661-5

12 Kleiger RE, Miller JP, Bigger JT Jr, Moss AJ, and the Multicenter Post Infarction Research Group. Decreased heart rate variability and its association with increased mortality after acute myocardial infarction. $A m \neq$ Cardiol 1987;59:256-62.

13 Pedretti R, Gementl A, Etro D, Bonelli R, Laporta A Maslowsky F, Carù B. Role of heart rate variability in patients at high risk of arrhythmic events after acute myocardial infarction. New Trends in Arrhythmias 1992; vili:433-6.

14 Casolo G, Balli E, Taddei T, Amuhasi J, Gori C. Decreased spontaneous heart rate variability in conges Decreased spontaneous heart rate variability in
tive heart failure. $A m \mp$ Cardiol $1989 ; 64: 1162-7$.

15 Coumel P, Hermida JS, Wennerblöm B, Leenhardt A Maison-Blanche P, Cauchemez B. Heart rate variability in left ventricular hypertrophy and heart failure, and the effects of beta-blockade. A non-spectral analysis of heart rate variability in the frequency domain and in the time domain. Eur Heart f 1991;12:412-22.

16 Saul JP, Arai Y, Berger RD, Lilly LS, Colucci WS, Cohe RJ. Assessment of autonomic regulation in chronic congestive heart failure by heart rate spectral analysis. $A m \mathcal{F}$ Cardiol 1988;61:1292-9.

17 Huikuri HV, Linnaluoto MK, Seppänen T, Airaksinen KEJ, Kessler KM, Takkunen JT, Myerburg RJ. Circadian rhythm of heart rate variability in survivors of cardiac arrest. $A m \mathcal{F}$ Cardiol 1992;70:610-5.

18 Dougherty CM, Burr RL. Comparison of heart rate variability in survivors and nonsurvivors of sudden cardiac arrest. Am $\mathcal{F}$ Cardiol 1992;70:441-8.

19 Hull SS Jr, Evans AR, Vanoli E, Adamson PB, StrambaBadiale M, Albert DE, et al. Heart rate variability before and after myocardial infarction in conscious dogs at high and low risk of sudden death. $\mathcal{F} \mathrm{Am}$ Coll Cardiol 1990; 16:978-85.

20 Billman GE, Hoskins RS. Time-series analysis of heart rate variability during submaximal exercise. Evidence for rate variability during submaximal exercise. Evidence for reduced cardiac vagal tone in animals susceptible

21 Pagani M, Lombardi F, Guzzetti S, Rimoldi O, Furlan R, Pizzinelli $P$, et al. Power spectral analysis of heart rate and arterial pressure variabilities as a marker of sympatho-vagal interaction in man and conscious dog. Circ Res 1986;59:178-93.

22 Hirsch JA, Bishop B. Respiratory sinus arrhythmia in humans: how breathing pattern modulates heart rate. Am $\mathcal{F}$ Physiol 1981;241:H620-9.
23 Hellman JB, Stacy RW. Variation of respiratory sinus arrhythmia with age. $\mathcal{F}$ Appl Physiol 1976;41:734-8.

24 Olshausen KV, Stienen U, Math D, Schwartz F, Kübler W, Meyer J. Long-term prognostic significance of ventricular arrhythmias in idiopathic dilated cardiomyopathy. Am F Cardiol 1988;61:146-51.

25 Ikegawa $T$, Chino $M$, Hasegawa $H$, Usuba $F$, Suzuki $S$, Ookura M, Nishikawa K. Prognostic significance of 24hour ambulatory electrocardiographic monitoring in patients with dilated cardiomyopathy: a prospective study. Clin Cardiol 1987;10:78-82.

26 Willens HJ, Blevins RD, Wrisley D, Antonishen D, Reinstein $D$, Rubenfire $M$. The prognostic value of functional capacity in patients with mild to moderate heart failure. Am Heart $₹$ 1987; 114:377-82.

27 Franciosa JA. Why patients with heart failure die: hemodynamic and functional determinants of survival. Circulation 1987;75(5):IV20-7.

28 Greene HL, Richardson DW, Barker AH, Roden DM, Capone RJ, Echt DS, et al. Classification of deaths after myocardial infarction as arrhythmic or nonarrhythmic (the cardiac arrhythmia pilot study). Am $\mathcal{f}$ Cardiol 1989; 63:1-6.

29 Shin SJ, Tapp WN, Reisman SS, Natelson BH. Assessment of autonomic regulation of heart rate variability by the method of complex demodulation. IEEE Trans Biomed Eng 1989;36:274-83.

30 Lipsitz LA, Mietus J, Moody GB, Goldberger AL. Spectral characteristics of heart rate variability before and during postural tilt. Relations to aging and risk of syncope. Circulation 1990;81:1803-10.

31 Vybiral T, Bryg RJ, Maddens ME, Boden WE. Effect of passive tilt on sympathetic and parasympathetic components of heart rate variability in normal subjects. $A m \mathcal{F}$ Cardiol 1989;63:1117-20.

32 Huikuri HV, Kessler KM, Terracall E, Castellanos A, Linnaluoto MK, Myerburg RJ. Reproducibility and circadian thythm of heart rate variability in healthy subjects. Am ₹ Cardiol 1990;65:391-3.

33 Pomeranz B, Macaulay RJB, Caudill MA, Kutz I, Adam $\mathrm{D}$, Gordon $\mathrm{D}$, et al. Assessment of autonomic function in humans by heart rate spectral analysis. Am $\mathcal{f}$ Physiol 1985;248:H151-3.

34 Akselrod S, Gordon D, Ubel FA, Shannon DC, Barger AC, Cohen RJ. Power spectrum analysis of heart rate fluctuation: a quantitative probe of beat-to-beat cardiofluctuation: a quantitative probe of beat-

35 Pitt $\mathrm{B}$. The role of $\beta$-adrenergic blocking agents in preventing sudden cardiac death. Circulation 1992;85(suppl venting sudde.

36 Eriksson H, Svárdsudd K, Larsson B, Ohlson LO, Tibblin G, Welin L, Wilhelmsen L. Risk factors for heart failure in the general population: the study of men born in 1913. Eur Heart $f$ 1989;10:647-56.

37 Nolan J, Flapan AD, Capewell S, MacDonald TM, Neilson JMM, Ewing DJ. Decreased cardiac parasympathetic activity in chronic heart failure and its relation to left ventricular function. Br Heart $\mathcal{f} 1992 ; 67: 482-5$.

38 Ahnve $\mathrm{S}$. Is QT interval prolongation a strong or weak predictor for cardiac death? Circulation 1991;84:1862-5.

39 Kawamoto A, Shimada K, Matsubayashi K, Chikamori T, Kuzume O, Ogura H, Ozawa T. Cardiovascular regulatory functions in elderly patients with hypertension. Hypertension 1989;13:401-7.

40 Schwartz PJ, La Rovere MT, Vanoli E. Autonomic nervous system and sudden cardiac death. Experimental basis and clinical observations for post-myocardial infarction risk stratification. Circulation 1992;85(suppl I):I-77-91.

41 Michelson EL, Morganroth J. Spontaneous variability of complex ventricular arrhythmias detected by long-term electrocardiographic recording. Circulation 1980;61: 690-5.

42 Anastasiou-Nana MI, Menlove RL, Nanas JN, Mason JW. Spontaneous variability of ventricular arrhythmias in patients with chronic heart failure. Am Heart $\mathcal{F} 1991$;122 1007-15.

43 Cardillo C, Musumeci V, Mores N, Guerrera G, Melina $D$, Folli $G$. Heart rate variability and ventricular ectopic activity in hypertensive patients. $\mathcal{F}$ Hypertens Suppl 1989; 7:S34-5

44 Luu M, Stevenson WG, Stevenson LW, Baron K, Walden J. Diverse mechanisms of unexpected cardiac arrest in advanced heart failure. Circulation 1989;80:1675-80. 